Allen James Gomez, Benzar Glen S. Grepon, Nelson G. Liwanen, Jr., Cyril Jane C. Ranido

\title{
Faculty Attendance Monitoring System: An improved feature with Barcode Scanner
}

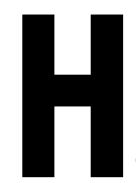

igher education institutions (HEls) seek ways to help students succeed at school. One way to make them academically successful is to ensure the regular attendance of the faculty at their classes. ${ }^{1}$ The importance of the teachers' attendance at class is undeniable. Their attendance motivates students to attend their classes (Brewer, 2005), and students' presence in the class signifies a transfer of knowledge from the teacher to the students and vice versa.

The HEIs have their own way of monitoring the attendance of their faculty. Some schools use logbooks while some use computer-based systems such as biometrics, Radio Frequency Identification (RFID,) and barcodes. Each of the attendance monitoring systems has its own advantages and disadvantages. For one, the biometric system is basically used for identification (Bigun, 2004) and verification (Jain, 2004). Such system has three advantages in terms of accountability, efficiency, and profit. However, the system's verification function does not work all the time with all types of biometrics (Taniola, 2014). Olatunbosun et al. (2013) developed an RFID-based student attendance management system. The system is time efficient and ensures accurate data entry. Barcodes, on the other hand, are used to increase the speed and accuracy of reading and entering data (gdom.net). Barcodes are used in events, travel, movies, advertisements, and games (Kostanecki, 2014). Moreover, they are often seen in various products sold in malls and supermarkets, making cashiering and POS faster.

1 The research study and writing for this paper was divided as such: Allen James C. Gomez conceptualized the study, the software development, and paper writing; Nelson G. Liwanen, Jr and Benzar Glen S. Grepon gathered the review of related literature; Cyril Jane C. Ranido managed the conduct of the study and edited the final paper. 
Many organizations are already embracing barcoding for their daily transactions. In the academe, Capitol University uses barcodes in the Identification Card of students and employees. Barcoded ID is used for borrowing and returning books. Some schools are using the barcode technology in monitoring the attendance of their students and faculty. In Malaysia, N.L.B. Mahmod (n.d.) developed a student attendance online system using a barcode reader. It was develo ped to help the lecturers monitor the attendance of their students. In India, a barcode-based student attendance system was also developed to improve the operational efficiency and effectiveness of attendance checking (K.Lakshmi Sudha, et al., 2015).

Capitol University uses the biometric system, particularly the fingerprint scanner, in checking the attendance of its employees. However, the system is limited to log-in and log-out. It does not monitor the faculty's attendance per subject schedule, which is done through a room-to-room checking by a student assistant of each college. The traditional system of monitoring the attendance of the faculty per schedule consumes time and the signing of the logbook disrupts the class.

This study aimed at designing and developing for Capitol University a barcode-based faculty attendance system using the System Development Life Cycle, specifically the Waterfall Model, as framework. The development of the system was geared toward the improvement of the school's faculty attendance monitoring, making it efficient in terms of time, recording, and coverage.

\section{System Development}

The system was designed and developed using a framework known as System Development Life Cycle (SDLC), specifically the Waterfall approach. SDLC is a widely used framework for system development in many organizations, featuring several phases that mark the progress of the systems analysis and design effort (Hoffer et al., 2002). This framework allows system development to be more efficient by following processes to achieve the goals.

\section{Data Gathering}

The first phase of the waterfall model is data gathering. The researchers conducted an interview and a document review. Interviewed about the faculty attendance monitoring and reporting of the college 
were the secretary and the dean of Computer Studies. Documents reviewed were the following: Teacher's Load Report (TLR), attendance monitoring log, and summary of faculty attendance report.

\section{Analysis and Design}

Analysing the requirements is very important in designing the overall functionalities of the system. The analysis involved the consolidation of documents and identification of some interventions based on the data. After the analysis of the data, the researchers designed a database. Each of the developed software was incorporated into the database to ensure inclusion of all the data from the documents. Next, the researchers created a diagram design (Entity Relationship Diagram [ERD]and Data Flow Diagram [DFD]) that covered all of the automated system processes. The ERD and DFD show the step-by-step process of the automated system from accepting raw data, processing the electronic data, to producing information about the faculty's time log.

\section{Development}

After the process was completed, the researchers developed the program for time and attendance to process raw data and generate report of the faculty's logging (in and out). The software used for the program development included Xampp and Visual Studio. Xampp software was used to create a database design and store data while Visual Studio was used to create and develop time and attendance application, from the application design to the functionality of the modules in the application.

\section{Testing and Implementation}

System testing was the last phase that determined the accuracy of the automated system. The system must accurately compare the faculty's registered class schedule to the attendance logs of the faculty by scanning the barcodes using a barcode scanner. To properly test the automated system, the researchers implemented it to its target environment. During this phase, the researchers registered the TLR of the faculty of the College of Computer Studies in the Time and Attendance System. The registered faculty schedule was compared to the time and date when the faculty logged in and out of the system. Barcodes were attached at the back of the faculty's ID card. The information embedded in the barcodes was the faculty's ID number. Before and after class, the faculty swiped their ID through the barcode reader for class attendance. The automated system then picked the equivalent ID number of the barcode of the faculty ID and compared it to the registered faculty information. When 
the ID number matched with the ID number stored in the database, the system processed the attendance monitoring, retrieving the registered class schedule of the faculty and comparing it to the data (date and time) picked from the barcode scanner. If the faculty were already late from the class when the ID was swiped, the system would calculate the incurred number of minutes of tardiness.

\section{Evaluation}

The evaluation of the automated system was the final phase of the study. This phase requires validation of the systems output based on the specifications and expected outcome, which is the correctness of data generated by the system. To evaluate the correctness of the data, the researchers captured the time stamp (system login of the faculty) and compared it with the record of time generated by the system. Furthermore, the total count of time for tardiness generated by the system was also verified.

\section{System Output}

Figure 1 displays the output generated by the system on the registered class schedule of the faculty based on their respective Teacher's Load Report for first semester 2017-2018. The information displayed on the screen is used by the system to compare the actual date and time of Login and Log-out of the faculty and served as basis for the processing and generation of reports on the tardiness of the faculty as shown in Figure 2 and the Attendance of the faculty as shown in Figure 3. This module can display the class schedule either of one faculty or of all faculty at once.

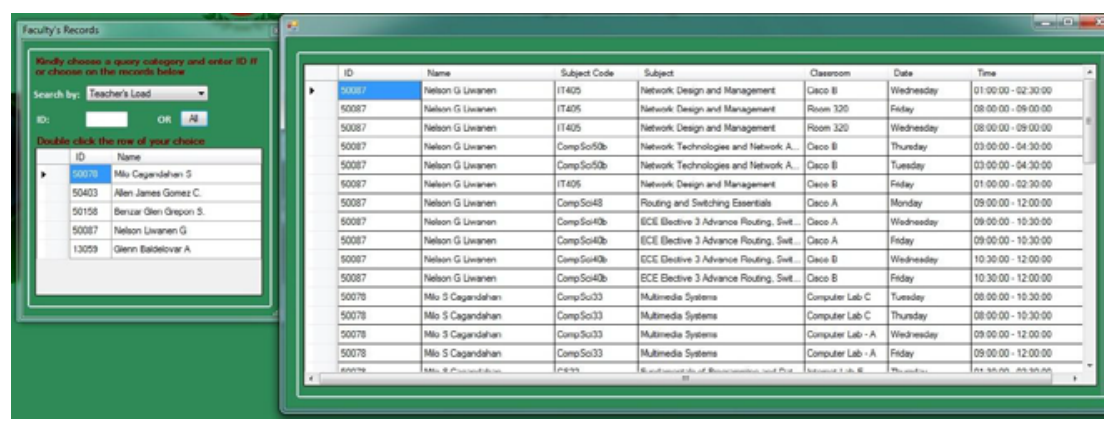

Fig. 1. Faculty Registered Schedules

Figure 2 is the screenshot of the actual report generated by the system on the actual log-in and log-out of the faculty. This module displays the total time of tardiness incurred by a faculty. The user must enter first the 


\section{4 | Research Notes}

ID number of a faculty for the system to display the attendance record of that faculty. The overall time of tardiness is found at the bottom right portion of the window box and has a font colour of red.

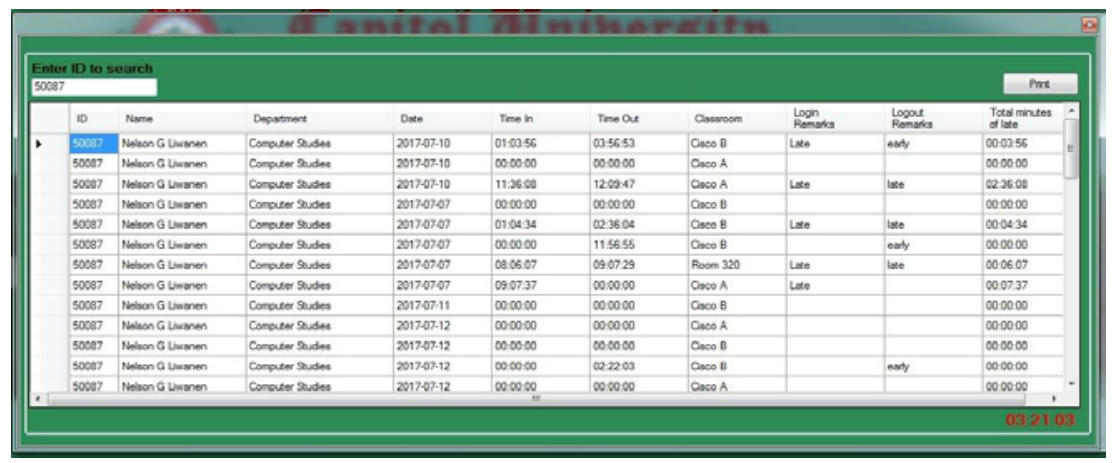

Fig. 2. Faculty's Total Time of Tardiness

Figure 3 is the screenshot of the actual attendance report generated by the system. This module provides a full detail of faculty attendance $\log$ report. This report specifies the faculty's time logs (in and out) on a particular date. The module also identifies the status of a faculty present or absent.

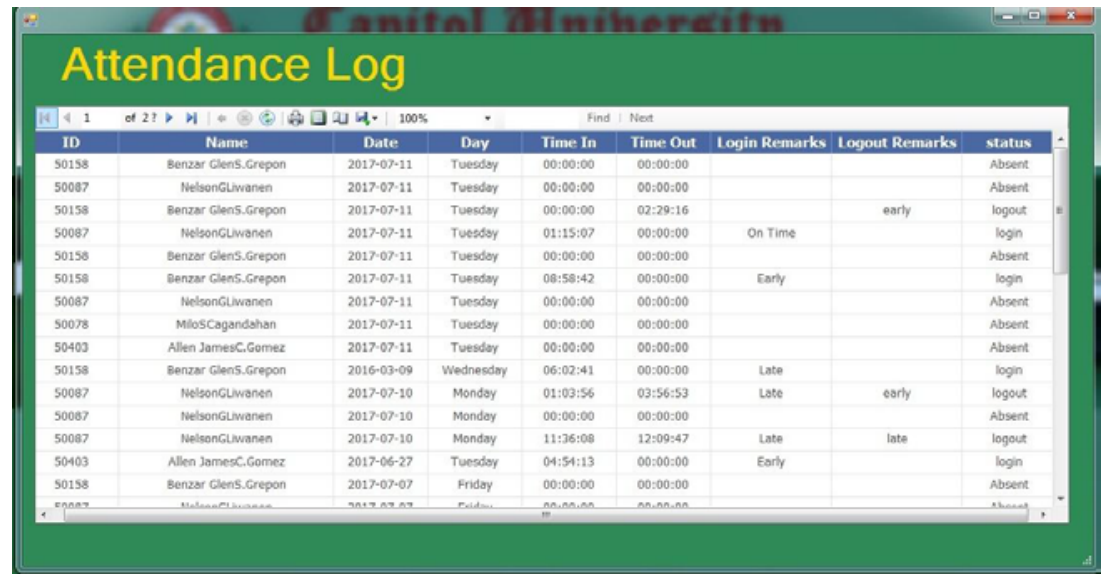

Fig. 3. Faculty Attendance Report 


\section{Conclusion and Recommendations}

After a couple of months of implementing and testing the system, the researchers conclude that the Faculty Attendance Monitoring System using the Barcode Scanner is very helpful in monitoring the faculty's attendance per subject schedule. The adoption of such system will increase the work productivity of the secretary of the College dean considering that most of the secretary's work is spent on monitoring the faculty attendance. Furthermore, the system compels the faculty to attend their respective classes on time and regularly as expected of them. Also, the system provides the administration with accurate reports on faculty attendance. To maximize the use of the system, the university may consider the following recommendations: 1) add to the system an application that captures actual classroom image based on the room planner, 2) install the system in every floor of the academic building, and 3) update the system by providing mechanisms that verify the status of faculty in cases of failure to login due to approved leave of absence.

\section{References}

Kostanecki, Matthew . 2014. Interesting Uses of Barcodes. Retrieved July 05, 2017 from https://www.inflowinventory.com/blog/interestinguses-barcodes/

Mahmod, N. No date. Student Attendance Online System Using Barcode Reader. Retrieved August 1, 2017 from http://umpir.ump. edu.my/3696/1/NURUL_LIYANA_BINTI_MAHMOD.PDF

Sudha, K., Shinde, S., Thomas, T., and Abdugani, A. 2016. Retrieved June 6, 2017 Http://journal.ru/wp-content/uploads/2016/08/d-2016-154. pdf. Barcode based Student Attendance System, 119(2), 2015th ser. doi:10.18411/d-2016-154

Brewer, E. 2005. "Professor's Role in Motivating Students to Attend Class ." Journal of Industrial Teacher Education. Retrieved July 6, 2017, from http://scholar.lib.vt.edu/ejournals/JITE/v42n3/pdf/brewer.pdf

J. Ortega-Garcia, J. Bigun, D. Reynolds and J.Gonzalez Rodriguez. 2004. "Authentication gets personal with biometrics"Signal Processing Magazine 21(2):50-62. 


\section{6 | Research Notes}

Anil K. Jain, Arun Ross and Salil Prabhakar. 2004. "An introduction to biometric recognition." IEEE Transactions on Circuits and Systems for Video Technology 14(1):4 - 20.

Taniola, J. 2014. Biometric Attendance System: Advantages and disadvantages. Retrieved June 05, 2017 from https:// physicalsciencesiv.wordpress.com/2014/09/23/biometricattendance-system-advantages-and-disadvantages/

Arulogun, O., Olatunbosun, A., Fakolujo, O., and Olaniyi, O. 2013. "RFID-Based Students Attendance Management System." International Journal of Scientific \& Engineering Research, 4(2):19 Retrieved June 6, 2017 from https://www.ijser.org/researchpaper/ rfid-based-students-attendance-management-system.pdf. 


\section{About the Contributors}

Cyril Jane C. Ranido is Associate Professor 2 and the current Dean of the College of Computer Studies, Capitol University, Cagayan de Oor City. cj.ranido@g.cu.edu.ph

Allen James C. Gomez is Teacher 1 at Capitol Univesity Senior High School Department, Cagayan de Oro City.

Lengomz123@gmail.com

Benzar Glen S. Grepon is Assistant Professor 2 at the College of Computer Studies, Capitol Univesity, Cagayan de Oro City. Ben.itc@gmail.com

Nelson G. Liwanen, Jr. is Instructor 2 at the College of Computer Studies, Capitol University, Cagayan de Oro City. liwanen.nelson@gmail.com

Heidi Grace P Mendoza is Associate Professor at the College of Business Administration of Capitol University. She finished a doctoral degree in management at Xavier University-Ateneo de Cagayan. Mendoza is the current coordinator of the business administration practicum of the College of Business Administration.

Lyndon S. Meyor is a senior high school student of Capitol University. He did the study for the article with his high school teacher Aris Rusiana at Capitol University Basic Education Department where he finished First Honors in his Grade 10.

Herlie B. Ontoy is a professor at the College of Nursing, Capitol University. She is also the college's extension officer. She finished her doctoral studies in Management at Capitol University Gradute School.

Janet C. Parpa is Professor and Assistant Dean of the College of Education, Capitol Unviersity.

Aris A. Rusiana is a senior high school teacher of the Department of Education. Previously a high school teacher of physics at the Capitol University Basic Education Department. 


\section{Editorial Guidelines}

PROGRESSIO Journal on Human Development is the flagship journal of Capitol University. It advances the vision and mission statements of the university by initiating discussions on various aspects of development studies. It also attempts to further the professional interests of scholars by disseminating their research studies and showing its role and significance in improving the quality of life in the Philippines. PROGRESSIO is a peer-reviewed journal.

The journal accepts articles based on research. It accepts submissions that are multi-disciplinary but also those that speak about a particular discipline. Articles that emanate from both basic and applied research are also welcomed. Collaborative work from authors of various disciplines is especially encouraged, and contributions from international colleagues are desired.

\section{SUBMISSION PROCESS}

Submissions in soft copy or digital file (DVD format) must be sent to the Managing Editor via this email address cupublications@g.cu.edu. ph. Manuscripts must adhere to the style and format specifications of the Chicago Manual of Style. You may consult http://www. chicagomanualofstyle.org

\section{THE ARTICLES}

Research articles should not exceed 8,000 words in length; this number includes the list of references at the end of the article but does not include the abstract and 3-5 keywords. All texts should be written in Times New Roman, point 12, and double-space. An abstract of 150-200 words should be included in the submission. Accepted manuscripts and revised manuscripts may go beyond the word limit, but this has to be approved by the Editor-in-Chief first. Please indicate the word count on the title page.

A separate title page is required bearing the author's name, academic rank or position and institutional affiliation, abstract, and keyword 
of 3-5 words. For ease of coordination, please identify the author to communicate with the journal's editorial board in the case of articles with two or more authors.

PROGRESSIO follows the double-blind referee system, which means that the reviewers do not know the name of the author whose manuscript they are evaluating. In this case, authors are required to submit the manuscript with no author identifying information. References to the author's work will be anonymized as it will jeopardize the review process. For example, if the author is Maria Santos, a citation reading Santos 2010:78 will appear as (Author 2010:78) and should be the same case in the list of references.

Members of the editorial board may not submit manuscripts to PROGRESSIO.

\section{AUTHOR RESONSIBILITIES}

Authors are responsible for the content of their articles, accuracy of quotations and for legal rights to publish the submitted material, and in resubmitting for the editorial board's final acceptance. Manuscript submitted to PROGRESSIO should not be under simultaneous consideration by any other journal or have been published elsewhere in any form. A Publication Agreement will be sent to contributors upon receipt of the contribution.

\section{EVALUATION}

PROGRESSIO is a peer-reviewed journal. The review process comprises both an internal review by the editor-in-chief and the senior editors comprising the Board and an external review process by two reviewers. Authors are invited to suggest potential reviewers. However the editor-in-chief will not be bound by these suggestions. The editorial board decides on the publishability of the manuscripts after a thorough consideration of the reviewers' comments.

\section{The submission should have the following contents:}

1. Abstract with 150 words maximum

2. 3-5 keywords below the abstract

3. Introduction containing the following: (a) research problem and research objectives; (b) review of related literature which 
$60 \mid$ Editorial Guidelines

highlights only the most up-to-date and state of the art publications on the research problem; (c) perhaps, author wishes to add his interest in the research problem (briefly state this).

4. Methods

5. Results and Analysis

6. Conclusion

7. References 
CU Press Publications

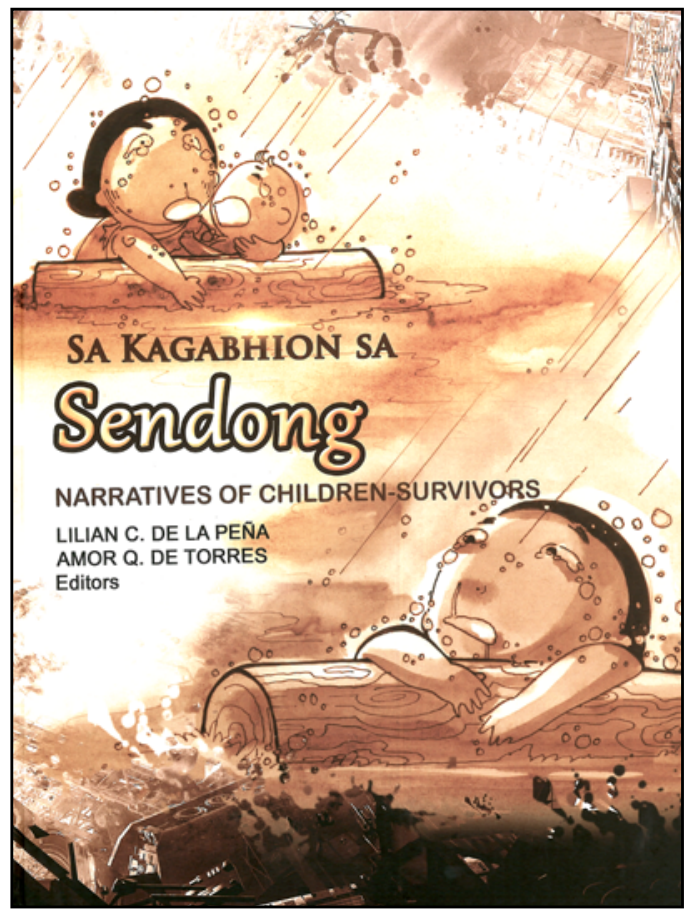

Sa Kagabhion sa Sendong: Narratives of Children Survivors Lilian C. De la Peña Amor Q. de Torres 2012

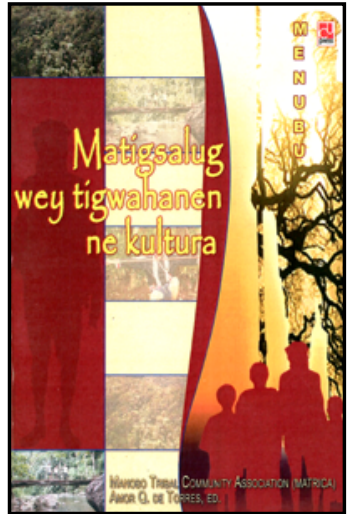

Matigsalug wey tigwahanen ne kultura Amor Q. de Torres 2008
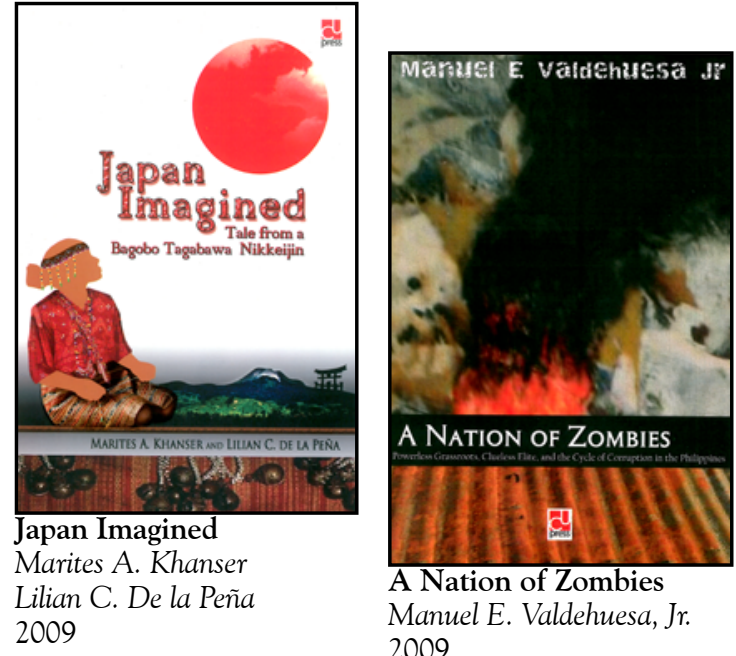

A Nation of Zombies Manuel E. Valdehuesa, Jr. 2009 


\section{PROGRESSIO}

Volume 9 | Number 1 | 2015

Articles

Heidi Grace P. Mendoza Consumer Ethnocentric Tendencies of Business College Students

Aris A. Rusiana

Lyndon S. Meyor

Illuminance in Classroom Under

Cloudy Weather Condition

Herlie B. Ontoy

Reflections on the Community Engagement of a Higher Education Institution in Northern Mindanao

Janet C. Parpa

Effectiveness of Language Games in Improving the English Oral Proficiency of Nautical Students

\section{Research Notes}

Allen James Gomez

Faculty Attendance Monitoring System Benzar Glen S. Grepon Nelson G. Liwanen, Jr. An Improved Feature with Barcord Scanner Cyril Jane C. Ranido 